\title{
Effect of botulinum toxin type-A in patients with focal spasticity
}

\author{
Esra Selimoglu ${ }^{1}$, Selin Turan Turgut' ${ }^{2}$, Pinar Akpinar ${ }^{3}$, Yasemin Yumusakhuylu ${ }^{4}$, \\ Sema Haliloglu ${ }^{5}$, Hatice Sule Baklacioglu ${ }^{6}$, Afitap Icagasioglu ${ }^{4}$ \\ ${ }^{1}$ Erenkoy Physical Medicine and Rehabilitation Hospital, Istanbul, Turkey; \\ 2Department of Physical Medicine and Rehabilitation, Karaman Government Hospital, Karaman, Turkey; \\ ${ }^{3}$ Department of Physical Medicine and Rehabilitation, Fatih Sultan Mehmet Training and Research Hospital, Istanbul, Turkey; \\ ${ }^{4}$ Department of Physical Medicine and Rehabilitation, Istanbul Medeniyet University, Goztepe Training and Research Hospital, \\ Istanbul, Turkey; \\ ${ }^{5}$ Department of Physical Medicine and Rehabilitation, Istanbul Occupational Disease Hospital, Istanbul, Turkey; \\ ${ }^{6}$ Department of Physical Medicine and Rehabilitation, Bakirkoy Prof. Dr. Mazhar Osman Psychology and Neurology Hospital, \\ Istanbul, Turkey
}

\begin{abstract}
OBJECTIVE: To investigate the effect of botulinum toxin type-A (BTX-A) on spasticity and function in patients with focal spasticity.

METHODS: Patients attended to the outpatient clinic of physical medicine and rehabilitation department with a diagnosis of focal spasticity and had BTX-A injections because of spasticty were evaluated for the study. Demographic data, exercise status, orthoses, drugs used for spasticity, functional status, stages of spasticity of muscles before and after $1^{\text {st }}$ and $3^{\text {rd }}$ months of BTX-A injection according to Modified Ashworth Scale (MAS) were evaluated retrospectively. MedCalc 11.6 statistical program was used for statistical analyses. Statistical significance was defined as $p<0.05$.
\end{abstract}

RESULTS: Forty-nine patients with focal spasticity were recruited for the study (35 men, 14 women). Mean age of the patients was $21.59 \pm 20.09$ years. The patients had cerebral palsy $(C P, n=28), 19$ had hemiplegia $(n=19)$ and paraplegia $(n=2)$. Forty-three patients were using orthoses and exercising regularly. Mean Pediatric Functional Independence Measurement (WeeFIM) scores of the patients with CP was 54.82 28.91 and according to the Gross Motor Function Classification System (GMFCS) the patients were in stages $2(14 \%), 3(46 \%), 4(11 \%)$ and 5 (29\%). Mean Functional Independence Measure (FIM) of hemiplegic and paraplegic patients was $80.80 \pm 20.88$. Brunnstrom staging scores for upper extremity $(3.52 \pm 0.96)$, hands $(2.68 \pm 0.82)$, lower extremity $(4.57 \pm 1.01)$ were calculated. MAS muscles demonstrated statistically significant decrease in spasticity at the end of first and third months $(p<0.05)$.

CONCLUSION: We saw a significant decrease in the spasticity of upper and lower extremities in patients with focal spasiticity who received BTX-A injections. We suggest that if BTX-A injections are supported with orthoses and exercise programs, then functional status of the patients would be better.

Key words: Botulinum toxin type-A; cerebral plasy; hemiplegia; spasticity.

Received: September 11, 2014 Accepted: November 18, 2014 Online: January 24, 2015

Correspondence: Dr. Esra SELIMOGLU. Erenkoy Fizik Tedavi ve Rehabilitasyon Hastanesi, Istanbul, Turkey.

Tel: +90 216 - 4118011 e-mail: esselimoglu@gmail.com

(c) Copyright 2014 by Istanbul Northern Anatolian Association of Public Hospitals - Available online at www.kuzeyklinikleri.com 
$S_{\text {in }}$ pasticity arises as a result of destructive changes in medulla spinalis or serebrum caused by trauma, stroke, hypoxia, inflammatory, and demyselinizing diseases, degenerative or familial diseases or compression by mass lesions. Muscle contraction amplitude decreases, muscle tone, and rigidity increases, and velocity dependent resistance during passive joint movements occur because normal inhibition of lower motor neurons which is required for the maintenance of physiological muscle tone is not achieved resulting in predominancy of upper motor neuron functions [1-3].

Spasticity is a complex disorder which may lead to serious disability [4]. Primary aim in its treatment is to achieve functional improvement. Among treatment targets increasing mobility, decreasing pain, and spasms, increasing ROM of joints, facilitating use of ortheses, and positioning, providing cosmetic benefit, prevention or postponing surgery can be enumerated $[5,6]$. Nowadays prophylactic treatment modalities applied for the treatment of spasticity include appropriate positioning, stretching, and exercises, physical therapy, oral antispastic drugs (baclofen, diazepam, tizanidine, and dantrolene), neuromuscular blockade with phenol or BTX-A, intratechal baclofen, and surgical interventions $[7,8]$.

BTX-A is the most potent neurotoxin produced by Clostridium botulinum. Via inhibition of acetylcholine release from presynaptic terminals of peripheral cholinergic nerves BTX-A prevents nervous signal transmission $[9,10]$. Nearly two or three moinths later, new nerve terminals develos through axonal budding, and nervous signal transmission resumes. Various studies have demonstrated that recovery of neuromuscular transmission, and secretion of acetylcholine are achieved nearly 91 days after BTX-A injection. It exerts its effect within the first week which peaks at 4.-6. weeks, and disappears generally within 3-4 months [11]. Thanks to its long-term, but reversible effect, ease of its application, appropriateness, and established safety, in addition to its favourable side effect profile, BTX-A has become the first choice in the pharmacological treatment of focal spasticity [12].

In this study the effect of BTX-A injections on spasticity in patients with focal spasticity has been retrospectively investigated.

\section{MATERIALS AND METHODS}

After retrieval of the ethics committee approval, the patients who were followed up, and received BTX-A injections in the outpatient clinic of Physical Medicine, and Rehabilitation Department with the diagnosis of focal spasticity were retrospectively evaluated. The patients with generalized spasticity, and those who developed contractures were excluded from the study. Patients' demographic data, their compliance to exercise therapy, orthoses, and antispastic drugs used, and their functional status were retrieved, and recorded via screening their medical files, The severity of spasticity evaluated for BTX-A injected muscle groups were evaluated before, and 1 , and 3 months after injections

\section{MAS criteria'}

\section{0 : No increase in muscle tone}

\section{1: Slight increase in muscle tone}

$1+$ : Minimal resistance at the end of the range of motion (ROM) of the affected mucle when the affected part(s) is moved in flexion or extension

2: More marked, but still slight increase in muscle tone; Minimal resistance felt throughout less than half of the ROM of the joint

3: Considerable increase in the muscle tone, difficulty during passive movements

4: Affected muscle part(s) are rigid in flexion or extension [7].

Study population consisted of the patients who received BTX-A injections, and diagnosed as focal spasticity, cerebral palsy (CP), hemiplegia, and paraplegia. Disease severity of CP patients according to Pediatric Functional Independence Measure (WeeFIM) scores, and their Gross Motor Function Classification levels, and also Functional Independence Measure (FIM), and Brunnstrom staging scores of the hemiplegic, and paraplegic patients were recorded, and all patients were included in the rehabilitation program.

For statistical Analysis MedCalc 11.6 statistical 
TABLE 1. Demographic data

\begin{tabular}{lcc} 
& $\mathrm{n}$ & $\%$ \\
\hline Gender & & \\
$\quad$ Female & 14 & 28.57 \\
$\quad$ Male & 35 & 71.42 \\
$\quad$ Diagnosis & & \\
$\quad$ Cerebral Palsy & 28 & 51.14 \\
$\quad$ Hemiplegia & 19 & 38.77 \\
$\quad$ Paraplegia & 2 & 4.08 \\
Orthoses & & \\
$\quad$ Users & 43 & 87.75 \\
$\quad$ Nonusers & 6 & 12.24 \\
Antispastics & & \\
$\quad$ Users & 18 & 36.73 \\
$\quad$ Nonusers & 31 & 63.26 \\
Exercise program & & \\
$\quad$ Compliants & & \\
$\quad$ Noncompliants & 43 & 87.75 \\
& 6 & 12.24 \\
\hline
\end{tabular}

program was used. $\mathrm{p}<0.05$ was accepted as the level of significance.

\section{RESULTS}

A total of 49 patients were included in the study. Demographic characteristics of the patients are demonstrated in Table 1 . The study population consisted of 35 male, and 14 female patients. Mean age of the patients was $21.59 \pm 20.09$ years. The patients were followed up with diagnosis of $\mathrm{CP}$ $(n=28)$, hemiplegia $(n=19)$, and paraplegia $(n=2)$. Forty-three patients were using orthoses, and exercising to maintain their positioning or range of motion, and functionality of the affected joint.

Mean WEEFIM score of the patients with CP was 54.82 \pm 28.91 . GMFCS, scores of the patients with CP are shown in Graphic 1. Mean FIM score of patients with hemiplegia, and paraplegia was $80.80 \pm 20.88$ Mean Brunnstrom staging scores of the patients were $3.52 \pm 0.96$ for the affected upper extremity, $2.68 \pm 0.82$ for the hand, and $4.57 \pm 1.01$ for the lower extremity. Pre-, and post-treatment 1 . (T1), and 3. (T3) month- MAS scores of the patients were also evaluated. Pre-, and post-treatment T1 spasticity levels were statistically significantly different $(p<0.05)$. Besides, post-treatment 1 (T1), and 3. (T3) month spasticity scores were also statistically significantly different $(p<0.05)$ (Table 2$)$.

\section{DISCUSSION}

This retrospective study was performed to demonstrate the effect of BTX-A injection on patients with focal spasticity 1 , and 3 months after injection. The results have demonstrated that BTX-A injection prominently decreased muscle tone.

Spasticity is a complex disorder which might lead to serious disability. BTX-A is used for multifocal, and focal spasticities. For the determina-

TABLE 2. BTX-A injected muscles, and their MAS (Modified Ashworth Scale) values

\begin{tabular}{lcccrr} 
Muscles & $(\mathrm{n})$ & $\begin{array}{c}\text { Onset of treatment } \\
\text { MEAN } \pm \text { SD }\end{array}$ & $\begin{array}{c}\text { 1. Month } \\
\text { MEAN } \pm \text { SD }\end{array}$ & $\begin{array}{c}\text { 3. Month } \\
\text { MEAN } \pm \text { SD }\end{array}$ & $p$ \\
\hline Biceps & 18 & $2.4 \pm 0.61$ & $1.5 \pm 0.7$ & $1.94 \pm 0.63$ & $<0.05$ \\
Flexor carpi radialis & 14 & $2.42 \pm 0.85$ & $1.35 \pm 0.84$ & $1.71 \pm 1.06$ & $<0.05$ \\
Flexor carpi ulnaris & 13 & $2.61 \pm 0.5$ & $1.46 \pm 0.77$ & $1.69 \pm 0.75$ & $<0.05$ \\
Flexor digitorum superficialis & 12 & $2.58 \pm 0.51$ & $1.5 \pm 0.75$ & $1.75 \pm 0.45$ & $<0.05$ \\
Flexor digitorum profundus & 11 & $2.63 \pm 0.5$ & $1.63 \pm 0.67$ & $1.72 \pm 0.46$ & $<0.05$ \\
Adductor muscles of the hip & 18 & $2.38 \pm 0.69$ & $1.33 \pm 0.76$ & $1.72 \pm 1.01$ & $<0.05$ \\
Hamstring & & $2.38 \pm 0.65$ & $1.33 \pm 0.76$ & $2.23 \pm 0.92$ & $<0.05$ \\
Gastrosoleus & 35 & $2.48 \pm 0.56$ & $1.48 \pm 0.61$ & $1.94 \pm 0.72$ & $<0.05$
\end{tabular}




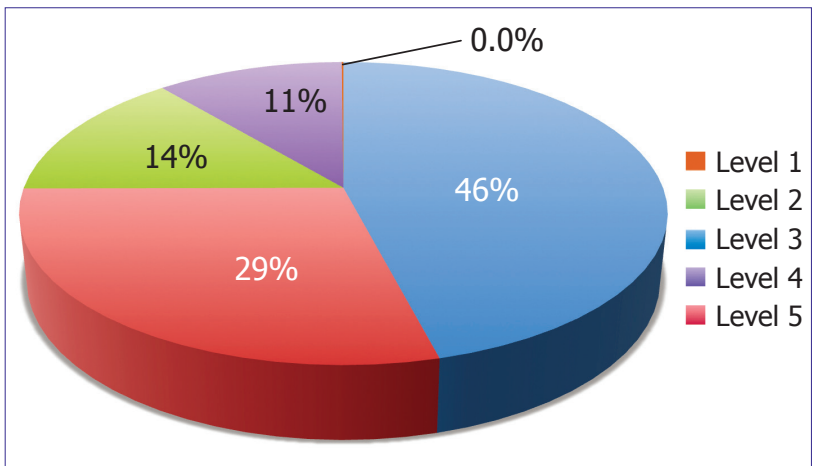

FIGURE 1. Distribution of the patients with cerebral palsy based on their GMFCS (Gross Motor Function Classification) scores.

tion of spasticity, and evaluation of its progression, physical, quantitative, and standardized scales have been used. Quantitative methods are preferred in randomized studies. Among them MAS is the most frequently used scale [8]. Slovek et al. injected a median dose of 255 IU botox to 18 stroke patients with upper extremity spasticity, and detected a significant regression in MAS values [13]. Simpson et al. investigated effectiveness of BTX-A on upper extremity spasticities in their randomized doubleblind, placebo controlled studies, and compared BTX-A 75/150/300 IU doses with placebo. The authors detected significant decrease in muscle tone 6 weeks after application of higher doses of BTXA [14]. In their randomized controlled studies, Scholtes et al. demonstrated the effect of BTX-A on muscle length, and walking parameters, and decrease in spasticity starting from the first week after injection. [15]. Brashear et al. injected 200-240 $\mathrm{U}$ botulinum toxin into wrist, and finger flexors of 126 patients who developed post-stroke spasticity, and detected significant regression in MAS values, improvement in hygiene, and also movements done during wearing clothes, and pain relief without any side effects [16]. Hesse et al. applied 400 units BTX-A to 12 patients with chronic lower extremity extensor spasticity, and and detected a significant regression of MAS values of 10 patients within 2 weeks [17]. Karaçam et al. analyzed 15 patients who developed post-stroke focal spasticity, and measures of spasticity (MAS), muscle strength score, disabil- ity scale, visual analogue scale, and Barthel index scores obtained at control visits performed at 1 , and 3. months were compared With this study they obtained a serious decrease in MAS, and disability scores. Another striking feature of the study is that effectiveness of BTX-A still continued at 3, month controls [7]. In some literature studies decrease in the effectiveness of BTX-A was reported at. 3. month controls, and this phenomenon was associated with severity of spasticity, inadequate doses, and inability to comply regularly with the rehabilitation program $[3,13,18]$. In this study, decreases in the severity of spasticity were detected at 1 , and 3. months based on MAS values of the patients who received BTX-A injections to their upper, and lower extremities, At 3. month controls of the patients, persistence of BTX-A effects can be associated with compliance of most of the patients to their exercise programs, and usage of appropriate doses. Physical therapy applications, therapeutic exercises, use of orthoses or plastering, electrical stimulation of BTX-A injected muscles, and biofeedback can be used after BTX-A injections [19]. Therapeutic exercises include traction/ stretching of BTX-A injected muscles, if active movements were noticed, then strength of antagonistic muscles were strenghtened, and neurofascilitative exercises were prescribed. Our patients were prescribed stretching exercises for BTX-A injected muscles, and if active muscle movements were noted, then these patients were included in the antagonistic muscle- strenghtening programs. Our 43 patients completed their exercise program.

\section{CONCLUSION}

Because of adverse effects of oral agents, in recent years for the treatment of spasticity, BTX-A injections have been used. Though various viewpoints have been proposed about effectiveness, and duration of BTX-A treatment, consensus opinion asserts that its effect is not sustainable Whatever the treatment choice for spasticity is, it should be supported by a neurohabilitative program.

Conflict of Interest: No conflict of interest was declared by the authors. 
Financial Disclosure: The authors declared that this study has received no financial support.

\section{REFERENCES}

1. Simpson DM. Clinical trials of botulinum toxin in the treatment of spasticity. Mayer NH, Simpson DM (eds). Spasticity: Etiology, Evaluation, Management and the Role of Botulinum Toxin. New York: We Move, 2002:125-30.

2. Little JW, Massgli TL. Spasticity and associated abnormalities of muscle tone. DeLisa JA, Gans BM (eds). Rehabilitation Medicine: Principles and Practice. Philadelphia: Lippincott-Raven Publishers 1998:997-1013.

3. Ozcakir S, Sivrioglu K. Botulinum toxin in poststroke spasticity. Clin Med Res 2007;5:132-8. CrossRef

4. Gracies JM. Pathophysiology of spastic paresis. I: Paresis and soft tissue changes. Muscle Nerve 2005;31:535-51. CrossRef

5. Burke D. Spasticity as an adaptation to pyramidal tract injury. Adv Neurol 1988;47:401-23.

6. Umphred DA, McCormack GL. Classification of common facilitatory and inhibitory treatment techniques. In: Umphred DA (ed). Neurological Rehabilitation. Missouri: Mosby 1990:11161.

7. Karaçam M, Selçuki D. İnme sonrası gelişen spastisite tedavisinde botulinum toksin A intramusküler enjeksiyonu etkinliği. Turk Norol Derg 2010;16:133-40.

8. Coban A, Matur Z, Hanagasi HA, Parman Y. Iatrogenic botulism after botulinum toxin type A injections. Clin Neuropharmacol 2010;33:158-60. CrossRef

9. Mayer NH. Clinicophysiologic concepts of spasticity and motor dysfunction in adults with an upper motoneuron lesion. Muscle Nerve Suppl 1997;6:1-13. CrossRef
10. Denny-Brown D. The cerebral control of movement. Liverpool: Liverpool University Press 1966:124-43, 171-84.

11. Coffield J, Comsidine RV, Simpson LL. The site and mechanism of action of botulinum neurotoxin. In: Jankovic J, Hallett(eds). Therapy with botulinum toxin. Marcel Dekker 1994:3-13.

12. Farmer SF, Harrison LM, Ingram DA, Stephens JA. Plasticity of central motor pathways in children with hemiplegic cerebral palsy. Neurology 1991;41:1505-10. CrossRef

13. Slawek J, Bogucki A, Reclawowicz D. Botulinum toxin type A for upper limb spasticity following stroke: an open-label study with individualised, flexible injection regimens. Neurol Sci 2005;26:32-9. CrossRef

14. Simpson DM, Alexander DN, O’Brien CF, Tagliati M, Aswad AS, Leon JM, et al. Botulinum toxin type A in the treatment of upper extremity spasticity: a randomized, double-blind, placebocontrolled trial. Neurology 1996;46:1306-10. CrossRef

15. Scholtes VA, Dallmeijer AJ, Knol DL, Speth LA, Maathuis CG, Jongerius $\mathrm{PH}$, et al. Effect of multilevel botulinum toxin a and comprehensive rehabilitation on gait in cerebral palsy. Pediatr Neurol 2007;36:30-9. CrossRef

16. Brashear A, McAfee AL, Kuhn ER, Fyffe J. Botulinum toxin type $B$ in upper-limb poststroke spasticity: a double-blind, placebo-controlled trial. Arch Phys Med Rehabil 2004;85:705-9. CrossRef

17. Hesse S, Lücke D, Malezic M, Bertelt C, Friedrich H, Gregoric $\mathrm{M}$, et al. Botulinum toxin treatment for lower limb extensor spasticity in chronic hemiparetic patients. J Neurol Neurosurg Psychiatry 1994;57:1321-4. CrossRef

18. Ward A, Roberts G, Warner J, Gillard S. Cost-effectiveness of botulinum toxin type a in the treatment of post-stroke spasticity. J Rehabil Med 2005;37:252-7. CrossRef

19. The We Move Spasticity Study Group. Mayer NH, Simpson DM (eds). Spasticity: Etiology,evaluation and management of spasticity, and the role of botulinum toxin. 2002;1-174. 